\title{
Oral microflora and dietary intake in infants with congenital heart disease: a case-control study
}

\section{Authors' response to comment by Booth}

\section{Stecksén-Blicks}

Published online: 3 April 2013

(C) European Academy of Paediatric Dentistry 2013

Dear Editor,

We are very well aware of the classical definition of a case-control study. However, in this study (Hansson et al. 2012), two groups of 6-month-old children were followed prospectively and compared concerning caries-associated microorganisms, which was related to dietary intake and medication. All children were caries-free at the endpoint. Similar studies where outcomes in subjects with rare conditions have been compared with outcomes in healthy controls exist in the literature, and they have been called case-control studies. As matching was performed on a group level, we think it was justified to compare continuous variables using analysis of variance (ANOVA) and for categorical variables to use the Chi-square test.

\section{Reference}

Hansson L, Rydberg A, Stecksen-Blicks C. Oral microflora and dietary intake in infants with congenital heart disease: a case control study. Eur Arch Paediatr Dent. 2012;13:238-43.
This reply refers to the comment available at doi:10.1007/s40368-013-0013-z.

C. Stecksén-Blicks ( $\square)$

Pediatric Dentistry, Department of Odontology, Faculty of Medicine, Umeå University,

S 90185 Umeå, Sweden

e-mail: Christina.stecksen-blicks@odont.umu.se 